\title{
Correction to: Conformational analysis of xylobiose by DFT quantum mechanics
}

\author{
Zhe Ling $\cdot$ J. Vincent Edwards $\cdot$ Sunghyun Nam $\cdot$ Feng Xu $($ D $\cdot$ Alfred D. French $(\mathbb{D}$
}

Published online: 28 July 2020

(C) Springer Nature B.V. 2020

\section{Correction to:}

Cellulose (2020) 27:1207-1224

https://doi.org/10.1007/s10570-019-02874-3

During the preparation of a follow-on manuscript, it was discovered that values of the temperatures of the distribution were miscalculated. The correct formula for the temperature is $\mathrm{T}=1 /($ coefficient $* \mathrm{R})$, where $\mathrm{R}=0.001987$ (the universal gas constant in $\mathrm{kcal} /(\mathrm{deg}$ mol) and coefficient is the parameter from the exponential curve fitting $y=\mathrm{e}^{- \text {coefficient } \cdot \mathrm{x}}$ where $\mathrm{y}$ is the probability of structures with each energy value, and $\mathrm{x}$ is the value of the energy.

In Table 2, the correct values for the first column of Temperatures

The original article can be found online at https:// doi.org/10.1007/s10570-019-02874-3.

Z. Ling · F. Xu ( $\bowtie)$

Beijing Key Laboratory of Lignocellulosic Chemistry, Beijing Forestry University, Beijing 100083, China e-mail: xfx315@bjfu.edu.cn

Present Address:

Z. Ling

Nanjing Forestry University, Nanjing 210037, China

Z. Ling · J. V. Edwards - S. Nam · A. D. French ( $\square)$

Agricultural Research Service, Southern Regional

Research Center, USDA, 1100 Robert E. Lee Blvd.,

New Orleans, LA 70124, USA

e-mail: al.french@ars.usda.gov

\begin{tabular}{lc}
\hline Solvated xylobiose, QM & 529 Correct \\
& value $=479$ \\
Solvated THP-O-THP, QM & vaz Correct \\
& value $=382$ \\
Martínez-Abad et al. (2017) Glycam & 542 Correct \\
POMF & value $=468$ \\
\hline
\end{tabular}

Publisher's Note Springer Nature remains neutral with regard to jurisdictional claims in published maps and institutional affiliations. 